\title{
Thinking differently? Autism and Quality of Life.
}

\section{Structured Abstract}

\section{Purpose}

This study explores perceptions of Quality of Life (QOL) of people with a learning disability and autism to facilitate a better understanding for clinical practice.

\section{Design/Methodology/Approach}

Mixed methods were used to gain perceptions of QOL from 20 individuals referred to their local diagnostic service. Individuals completed questionnaires which were compared with previous studies and participated in in-depth interviews which were thematically analysed. All data was contextualised in case examples.

\section{Findings}

Subjective wellbeing scores were lower than found in previous research. Social communication was raised extensively describing both positive and negative perceptions. Consistent themes around the need for tailored social support and the value autonomy over environment were raised.

\section{Research Limitations/Implications}

The study was small in scale and limited to subjects who has been referred for a diagnostic service.

The study identified the need for further study and particularly in relation to the social communication domain of QoL and impact of stress and anxiety on QoL

\section{Originality/Value}

This study demonstrated that it is possible to access views from this group and that these views are nuanced. It suggests differences between reported QoL in people with learning disabilities who are and who are not autistic. Service design and individual approaches could be improved by a better understanding of different QoL perceptions of this group 


\section{Introduction}

There is a commonly held perception that people with a diagnosis of an Autism Spectrum Condition (ASC) can show differences in their perception of the world (Attwood 2001). A number of studies suggest structural and functional differences in the brain for Autistic individuals compared with those without the diagnosis (Braden et al 2017, McAlonan et al 2002). It is therefore reasonable to consider the possibility that Autistic individuals may perceive their Quality of Life (QoL) differently to those without this diagnosis.

Previous studies have suggested that perceptions of subjective QoL for people with a learning disability are the same or more positive that for the ordinary population (Verri 1999, McGillivray et al 2009). Some studies suggest less positive perceptions for Autistic people (Jamison and Shuttler 2015, Shipman et al 2011, Punshon et al 2009, JennesCoussens et al 2006)

This paper presents evaluation of theories of QoL and literature in relation to learning disability and ASC. It will outline a small-scale study exploring QoL perceptions for a group of participants with mild or 
borderline learning disability and ASC and consider the relevance of this to current thinking and practice.

\section{Literature relating to QoL, Learning Disability and Autism}

QoL is a complex concept with as many as 44 definitions (Brown and Brown 2005, Hughes et al 1995) with some key areas of agreement in the literature (Kober 2010). Firstly, that QoL is viewed as a global, overarching concept. This indicates an acceptance of a multidimensional model. Secondly, QoL is a fundamentally subjective concept in nature (Cummins 2015). Thirdly, a further demarcation of these dimensions is that they can be described as objective or subjective

Kober (2010) identifies (in order of frequency of mention) a range of domains of QoL: interpersonal relations, social inclusion, personal development, physical wellbeing, self-determination, material wellbeing, emotional wellbeing, rights, family, recreation and leisure and safety and security. Perceptions may vary in these different domains at given times, meaning that any measure would have to be nuanced to measure across these domains rather than assume that an overall measure presented an accurate picture. 
Objective measures of wellbeing describe more concrete aspects of life, such as a particular wage, number of friends or type of accommodation. Subjective measures describe individual perceptions and a personal measure of satisfaction with an aspect of life.

Subjective and objective measures can contradict each other within an individual. For example, a person may be able to describe many friends and social interactions but may describe a sense of dissatisfaction with the quality or nature of these relationships. There is potential for apparently objective measures that are gathered from individuals directly to vary from those who provide care for them. For example, 'How many friends do you see each day?' or 'How often are you engaged in a social activity each day' may appeared to be gathering a concrete aspect of life but in fact depend on a personal perception of what a friend or a social activity might be. 
Zapft (1984) presented a helpful model of potential patterns of subjective and objective wellbeing

\begin{tabular}{|l|lc|}
\hline Objective Living Conditions & Subjective Living Conditions \\
\hline & Good Bad \\
\hline Good & WELL-BEING DISSONANCE \\
\hline Bad & ADAPTATION. DEPRIVATION \\
\hline
\end{tabular}

Table 1 showing Zapft's model of wellbeing, taken from Rapley (2006)

Rapley (2006) applied Zapft's (1984) paper to current thinking and presents descriptive states reflecting different combinations of subjective and objective wellbeing. In Table 1 a person with positive objective and subjective indicators is described as being in a state of 'wellbeing'. Negative objective indicators with positive subjective indicators reflect an individual 'adapting' to his/her difficult situation which allows functioning but against adversity. Positive objective indicators and poor subjective indicators reflect a 'dissonant' state and negative indicators across both reflect a perceived 'deprived' state. 
Zapft suggested that the majority of people can function and develop in a state of wellbeing or adaptation. He believed that the dissonant and deprived states were more likely to have a disruptive impact on daily functioning.

It is well documented that beyond the extremes of wealth or abject poverty, that individuals have a remarkable stability in the subjective satisfaction levels in key domains and life in general (Cummins and Lau 2005). Individuals generally report a level of $70-80 \%$ satisfaction with life, in spite of a number of life circumstances (objective indicators) that would be assumed to impact upon them. In combination with Zapft's theory this would suggest that the majority of people function in a state of adaptation from averse objective circumstances or in a state of wellbeing. One theory put forward by Cummins et al (2010) and described by Shalock et al (2010) to explain how this stability occurs in adversity is homeostatic theory. It suggests a basic human survival mechanism which allows factors such as money or close relationships to act as shields against adversity, allowing people to rate their perceptions of their lives more highly at times when other aspects appear more negative. 
Research specifically exploring the area of QoL for people with learning disability and autism has been limited in its scope. Plimley (2007) highlighted a tendency for researchers to focus on carer's perception of the QoL of individuals with ASC and a learning disability, rather than directly seeking the individual's view, as well as a tendency to focus on objective rather than subjective measures of QoL. Whilst some studies suggest that proxy reports can be helpful (Schwartz and Rabinovitz 2003), others suggest that they may be more broadly inaccurate and particularly flawed in specific domains, such as social interaction (Sheldrick et al 2012).

Verri et al (1999) used the Comprehensive Quality of Life Scale (COMQOL-ID) (Cummins and Lau 1997) with 150 people with mild and moderate learning disability in Australia. The tools used in this study had been specifically adapted for valid and reliable use with participants with a learning disability, with some standardised and supportive visual scales and a pre-test to ensure full understanding. Objective QoL indicators (such as type of accommodation, number of interactions and income) gathered in this study were generally scored lower than those gathered from an ordinary population. 
Studies that have attempted to gather objective QoL data about people with a learning disability have suggested generally lower scores than the ordinary population (García-Villamissar et al 2013; Billstedt et al 2011, Gerber et al, 2008; Saldana et al 2009; Persson, 2000).

McGillivray et al (2009) carried out a study using the Personal Wellbeing Index (PWI-ID) (Cummings and Lau 2005). This tool is specifically designed for people with a learning disability and a pre-test protocol provides visual scales that can be used for the individual to rate their subjective satisfaction in a number of domains. This was completed with 112 participants with mild and moderate learning disability and found subjective wellbeing measure to be generally high and stable. This study specifically excluded Autistic subjects.

These studies suggested the potential for a majority of people with learning disabilities to be in Zapft's adaptive state where subjective perceptions were very stable and relatively high (McGillivray et al 2009) in spite of more negative objective indicators (Verri et al1999).

A small number of studies have also tried to look in more detail at the subjective QoL perceptions of people with ASC, which have mainly involved a carer's views. A meta-analysis of 10 studies of primarily 
children and a small number of adults without a learning disability (van Heijst and Geurta 2014), showed that the most different domain for Autistic subjects was social functioning, with examples such as greater emphasis on family than friendship. Overall QoL was reported to be lower for Autistic people.

There have been some smaller scale studies that directly involve Autistic individuals, and these focussed on people described as having Asperger Syndrome, therefore more likely to exclude people with a formal diagnosis of learning disability (Jamison and Schuttler 2015, Shipman 2011, Punshon et al 2009, Jennes-Coussens et al 2006). These studies suggested lower levels of satisfaction with everyday activities, including employment (Jennes-Coussens et al. 2006). They also identified emotional themes such as alienation, frustration and depression (Jones et al. 2001). Bauminger \& Kasari (2000) highlighted the need to consider quality versus quantity in friendships, and loneliness, as a serious issue.

Jamison \& Schuttler, 2015 and Shipman 2011 suggested lower all-round QoL for Autistic participants, but particularly for those showing higher anxiety. There was also some suggestion that the degree of social 
support was a predictor of QoL for people described as having Asperger Syndrome (Burgess and Gutstein 2007).

These studies suggested that Zapft's adaptive patterns that could seen in literature relating to the QoL perceptions of people with a learning disability in less positive circumstances were not as visible in studies of Autistic people. This indicated value in exploring the QoL patterns for individuals with ASC and a mild learning disability to consider whether there may be differences from the learning-disabled population.

\section{Methods}

The first author of this paper carried out a small-scale study in one diagnostic service. A focus group of five Autistic people with learning disability assisted in developing methods for the study. Research interviews were all carried out by the first author. Information sheets using easy words and pictures were sent to potential participants whose $I Q$ range was identified as within the mild to borderline range (55-85). These sheets were designed by a Speech and Language Therapist and the focus group. Patients were contacted by telephone to see if they wished to participate. All 22 patients who were contacted were initially willing to take part. Ethical approval for the study was gained from the 
University of the West of England and the local Research Ethics Committee.

Consent to participate in the research was assessed using a local framework with any participants who expressed an interest. The initial session included the pre-assessment for the Personal Wellbeing Index (PWI-ID) (Cummings and Lau 2005) and COMQOL-ID standardised QoL questionnaires, which were previously used in Verri's 1999 and McGillivray's 2009 study.

All participants were identified as having capacity to consent to participate in research and the skills to complete the assessment tools with validity. One participant experienced a significant bereavement during the process and withdrew, one participant did not attend after initial engagement and no reason was directly given. This left 20 participants who formed the sample group.

The sample group represented 90 percent of the local service's clinical caseload of people with mild or borderline learning disability over a period of one year. The group were balanced for gender and ranged in age from 18 to 55. The group had mixed living arrangements with some in their own homes, some in supported living and some living with 
families. The majority were unemployed or in education and none were in full-time employment.

\section{Detail of the Study Methods}

Following a careful evaluation of the literature and a discussion with the author of the tools (Cummins 2012, personal correspondence) it was agreed that the most robust tools to measure QoL for this group combined the objective scales of the COMQOL-ID and the subjective scales of the PWI-ID. Limitations, identified by the tool author (Cummins 2002) in the importance and subjective scales of the COMQOL-ID meant that these were not used.

The main study used mixed methods and used the PWI-ID $(n=20)$ and the COMQOL-ID $(n=20)$, and the first eight participants completed an indepth qualitative interview. The tools and pre-assessment process selected reflected those used in previous studies (McGillivray et al 2009, Verri et al 1999), which allowed for some informal comparisons and discussion in study results.

A topic guide based on the QoL domains of the Personal Wellbeing Index was developed to support an in-depth qualitative interview. The questions used ethnographic elements, such as 'mini-tour' and 'grand 
tour' style questions to facilitate narrative. This was designed to triangulate and provide depth to the quantitative data. The quantitative data also provided a flexible prompt for the qualitative questions e.g. 'You told me you visit the doctor once a week, tell me more about that'. Pictorial supports were used throughout.

The interviews were video recorded to ensure non-verbal information was gathered, with audio pen used to improve reliability of audio quality. These were then transcribed in full recording both verbal and non-verbal data.

Descriptive analysis was carried out with the quantitative data and thematic analysis (Braun and Clarke 2006) was used to identify themes in the qualitative data

\section{Results}

Quantitative data

The use of the PWI-ID and COMQOL-ID tools in the present study allowed for descriptive visual comparisons with Verri (1999) and McGillivray's Studies. This aspect of the data was not subjected to statistical analysis. 


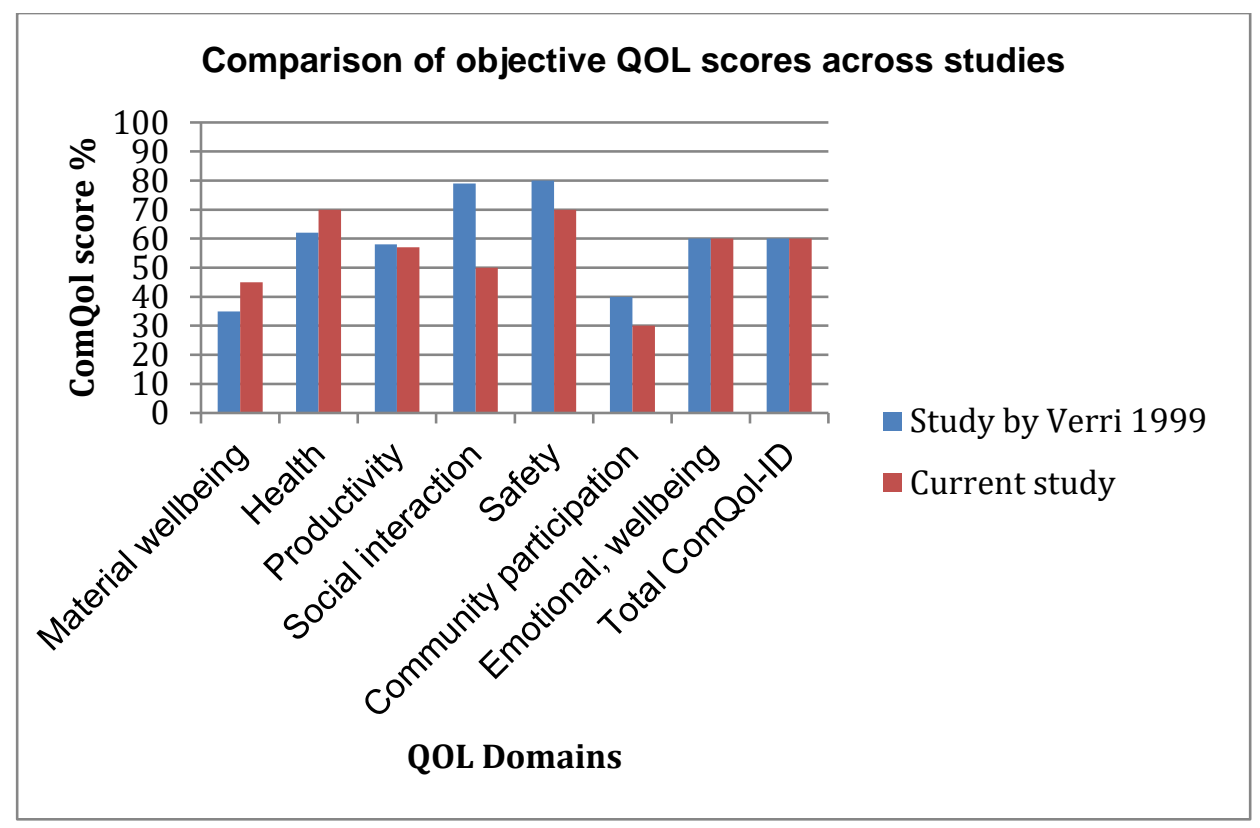

Figure 1 Comparison of scores of Verri's (1999) study and the present study

Figure 1 shows Verri's 1999 study of 150 people with a learning disability alongside the present study scores. This shows some similarities in patterns of objective wellbeing, such as visibly lower scores in the areas of material wellbeing and community participation and higher scores in the dimension of safety. The most notable differences are that the domain of health generally scores higher in the first author's study and the domain of social interaction scores less well. 


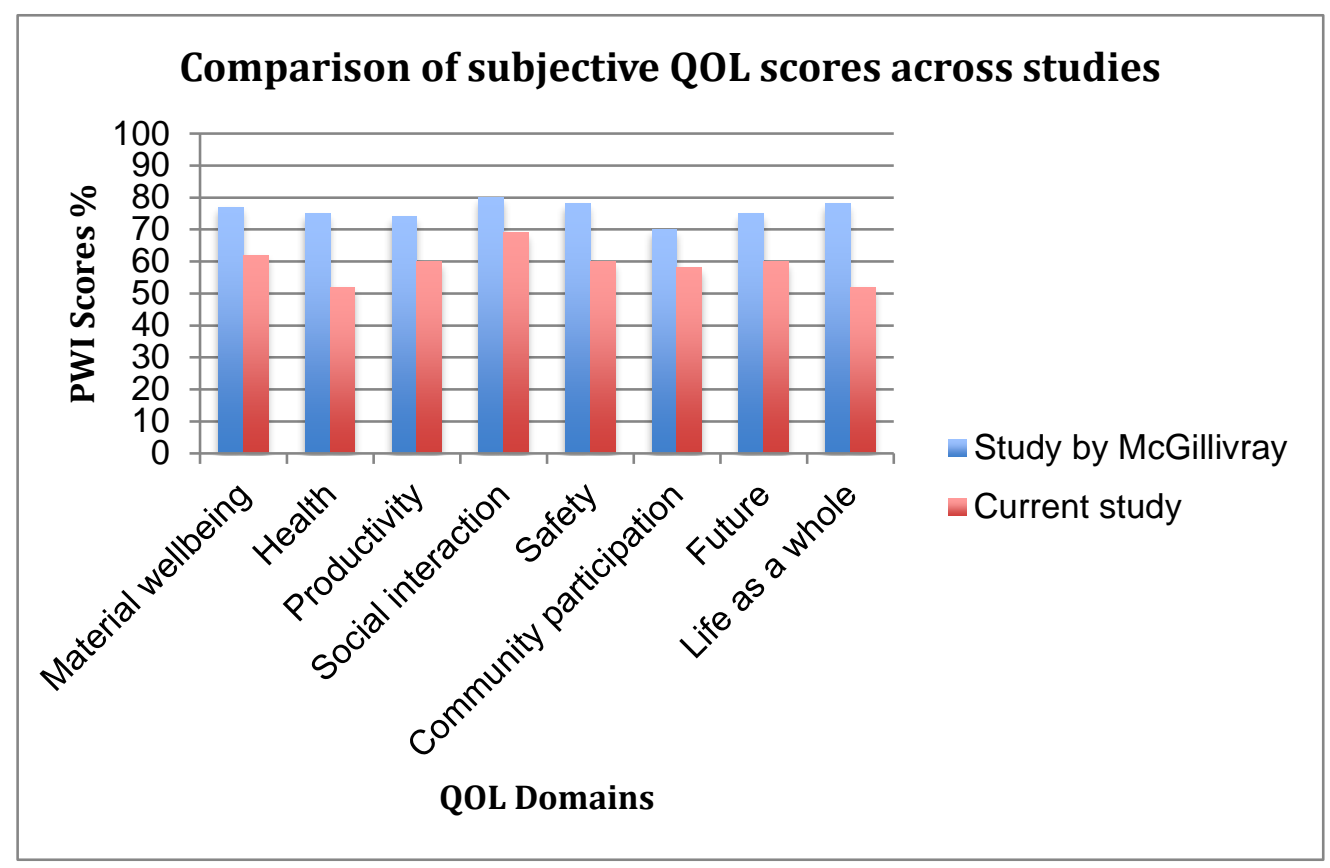

Figure 2: Chart showing mean PWI-ID scores across dimensions in McGillivray's 2009 study and the present research study

Figure 2 shows a comparison of the scores of 112 adults with learning disabilities (specifically excluding people with autism) who completed a Personal Wellbeing Index questionnaire (McGillivray et al 2009) with the present study. Overall the present author's study showed lower subjective scores than in McGillivray's study, with the lowest scoring areas being for health and when participants were asked to give their perceptions of 'life as a whole'. The highest subjective wellbeing scores in the first author's study were in the areas of social interaction and material wellbeing. 
The results suggest that this study group might not perceive their subjective QoL in the same consistent, positive or inflated way as predicted from the previous literature looking at people with only a learning disability.

\section{Qualitative data}

Thematic analysis of the qualitative data identified a wide range of subthemes, the largest number of these being in social interaction. Subthemes in this area were both positive (e.g. family and virtual friends are important) and negative (people do not understand me; I cannot express myself).

The interactive and complex nature of elements such as objective and subjective wellbeing and perceived importance on different domains were considered by presenting case examples.

It was noted that participants often expressed strong but apparently contradictory messages and themes in their interviews. For example, several emphasised the importance of particular individuals such as a partner or a parent to their well-being (People have value), but also how difficult these individuals were to manage in their environment (People are difficult). Another noted pattern was the value that participants 
placed on particular items or environments, which did not necessarily equate to their monetary or conventional social value.

\section{Case examples}

Individual case examples were selected based on Zapft's criteria and incorporated results of both quantitative and qualitative analysis. In all cases nicknames and adaptations have been used to protect identity.

\section{Adam- In deprivation}

Adam was a man in his twenties with a borderline learning disability. He lived with his partner and his two young children. He presented in a deprived state of wellbeing with a $50 \%$ score (converted) on his COMQOL-ID and a 39\% score on his PWI-ID (negative objective/negative subjective)

A: 'I just didn't have the right school... the right school help. I was always the one who got like left. Get on and do things by yourself and that.'

Adam expressed the view that his negative feelings about his life reflected the bad experiences that he had been through and was continuing to have. There was a strong sense that this was unfair and unchangeable.

A: 'I got to be more like "don't say nothing". Makes me, you know, 
makes me look like l'm nothing. They can take the mickey out of me.'

\section{Mark - In adaptation}

Mark was a man in his twenties who had a mild learning disability and ASC. He was unemployed and lived with his mother. Mark showed an adaptive pattern of wellbeing with a $55 \%$ score (converted) on his COMQOL-ID and a $72 \%$ score on his PWI-ID (Negative objective/positive subjective).

Mark place a heavy emphasis on objects and items in terms of his life satisfaction and was positive about the possibility of being able to spend time away from people. He values the presence of his mother in his environment but not interaction with her.

M. 'Possessions I like to buy and keep forever.' (Objects make me happy)

S: 'What in your everyday life helps you to do things well and be successful?'

M: 'Just doing it on my own with no-one around me.' (I need some time alone) 
In this example whilst Mark's obejctive QoL was poor, particularly in relation to social interaction, his perception was that being able to be away from people was positive.

\section{Jane - In wellbeing}

Jane was in an overall state of 'wellbeing' with $70 \%$ satisfaction on her COMQOL-ID (converted) and a 70\% score on the PWI-ID (Positive Objective/Positive Subjective). She was a young woman attending college, who had a borderline learing disability and ASC.

One example was that she felt positve about her ability to engage in the community and she could see some more objective signs of this:

$\boldsymbol{J}$ 'I think l've gotten better, l've gone out more... 'cos l've been to the shops on my own... I've done it as much, l've sort of worked myself to going out.' (I need to feel worthwhile)(Control is key)

\section{Discussion}

Subjective QoL was perceived more negatively for this group than might be expected from previous studies of individuals with a learning disability or the ordinary population. Many of this group were dealing with adverse objective circumstances and their lower subjective wellbeing scores suggests possible issues with resilience or adaptation to these circumstances. 
The qualitative analysis in this study suggested that perceptions of social interaction were an important factor in both negative and positive perceptions of wellbeing for this group. The way in which social interaction as a dimension of wellbeing is perceived may be different for people with autism. The ethnocentric assumption that a larger quantity of friendships and amount of face-to-face time spent with a people is a measure of its quality should be considered carefully when rating an autistic individual's QoL, with Mark being a good example of this. This links to the idea that whilst the participants like Mark found value in people in their lives, they could also find them extremely difficult and stressful if they demanded too much socially and emotionally.

One hypothesis in the area of QoL, used explain the relatively high, stable level of subjective wellbeing in the normative population, is homeostatic theory (Cummins et al 2015). This is the process of adaptation where an individual is able to flexibly consider their objectively negative situation and 'look on the bright side'. This is seen as a survival mechanism, based on the principal that people are likely function better when they are in a more positive state of wellbeing. In effect this is one way in which individuals can move from one of Zapft's 
more negative states to a more positive one, without their objective circumstances changing.

This process may require imaginative thinking and possibly even a degree of self-deception. Certainly, it would require some flexibility of thinking to be able to imagine that your current negative circumstances have a positive side to them. It does not seem unreasonable to suggest that an Autistic person may have neuropsychological differences that make them more likely to 'see things as they are'. Shalock (2010) suggests that if stress levels increase and no mechanism acts to balance this, the result is in a reduction in subjective wellbeing and this has been conceptualised as a factor in depressive illness.

Anxiety and stress is seen clinically as a significant area of challenge for Autistic people and their ability to cope with stress may also be key to understanding differences in perceptions of wellbeing. Hirvikoski and Blomqvist (2015) reported higher levels of stress for Autistic adults than neurotypical controls, with particular challenges in perceptions of stress and coping ability. Rosenthal et al (2013) suggest that executive functioning difficulties might impact on the ability to choose the best coping strategies. 
This study suggests the possibility that people with an additional diagnosis of Autism may need support or an adapted approach to manage stress and adversity in situations that others may appear to have more natural resources and mechanisms to manage.

\section{Conclusion}

This study suggests that Autistic people with a learning disability may show some differences in the way that they perceive their QoL from people with a learning disability and that this difference is relevant when supporting this group. This study was small in scale and limited to people who were actively seeking an autism diagnosis. This is an area that warrants further investigation. Particularly, consideration of the different ways that stress and adversity might impact on people with a diagnosis, and adaptations that could be required to ensure that they are well understood and supported. 


\section{References}

Attwood, T. (2001) Asperger's Syndrome: A guide for Parent and Professionals. London: Jessica Kingsley Publishers

Bauminger, N. and Kasari, C. (2000) Loneliness and Friendship in High-Functioning Children with Autism. Child Development [online]. 71 (2), pp.447-456. [Accessed 21/04/2014].

Billstedt, E., Gillberg, I.C. and Gillberg, C. (2011) Aspects of Quality of Life in adults diagnosed with autism in childhood: a population-based study. Autism: The International Journal of Research and Practice [online]. 15 (1), pp.7-20.

Braden.B.B., Smith.C.J., Thompson.A., Glaspy. T.K., Wood.E., Vatsa.D., Abbott.A.E., McGee.S.C., Baxter.L.C. (2017) Executive function and functional and structural brain differences in middle-age adults with autism spectrum. Autism Research. 10 (12), pp. 1945-1959 [accessed 27/03/2018]

Braun, V. and Clarke, V. (2013) Successful Quantitative Research. London: SAGE Publication Itd.

Brown, R.I. and Brown, I. (2005) The application of quality of life. Journal of Intellectual Disability Research [online]. 49 (10), pp.718-727.

Burgess, A.F. and Gutstein, S.E. (2007) Quality of life for people with autism: Raising the standard for evaluating successful outcomes. Child and Adolescent Mental Health [online]. 12 (2), pp.80-86. [Accessed 11/09/2011]. 
Cummins, R.A. (2002) Vale ComQol: Caveats to using the Comprehensive Quality of Life Scale. Welcome: The Personal Wellbeing Index. Available from: deakin.edu.au [Accessed June 2011].

Cummins, R.A, Lau, A.L.D., Davey, G., McGillivray, J. (2010) Measuring subjective wellbeing: The Personal Wellbeing Index- Intellectual Disability. In: Kober, R., ed. (2010) Enhancing the Quality of Life of People with Intellectual Disabilities. From Theory to Practice. London: Springer, pp.33-46.

Cummins, R.A (2015) Understanding quality of life in Medicine: A New Approach. Journal of the American College of Nutrition. 34 pp.4-9.

Commins, R.A (2012)- Personal email correspondence with author.

Cummins, R.A and Lau, A.L.D, (2005) Personal Wellbeing Index-Intellectual Disability. 3rd Edition. Manual. School of Psychology, Deakin University: Deakin University.

Cummins, R.A and Lau, A.L.D (1997). Comprehensive Quality of life scaleIntellectual/Cognitive Disability. $5^{\text {th }}$ Edition. Manual. School of psychology, Deakin University: Deakin University

García-Villamisar, D., Dattilo, J. and Matson, J.L. (2013) Quality of life as a mediator between behavioral challenges and autistic traits for adults with intellectual disabilities. Research in Autism Spectrum Disorders [online]. 7 (5), pp.624-629. [Accessed 01/04/2011]. 
Gerber, F., Baud, M.A., Giroud, M. and Carminati, G.G. (2008) Quality of life of adults with pervasive developmental disorders and intellectual disabilities. Journal of Autism \& Developmental Disorders [online]. 38 (9), pp.1654-1665. [Accessed 12/02/2012].

Hirvikoski,J. and Blomqvist, S. (2015) High perceived stress in intellectually able adults with autism spectrum disorder. Autism.19 (6) 764-768

Hughes, C., Bogseon, H., Jin-Ho, K. and Eisenman, L.T. \& Killian, D.J. (1995) Quality of life in applied research: A review and analysis of empirical measures. American Journal on Mental Retardation. 99 (6), pp.623-641.

Jamison, R. and Shuttler, J.O. (2015) Examining social competence, self-perception, quality of life, and internalizing and externalising symptoms in adolescent females with and without autism spectrum disorder: A quantitative design including betweengroups and correlational analysis. Understanding the links between sex/gender and autism. Molecular Autism [online]. 6(1): 53. [accessed 12/04/16]

Jennes-Coussens, M., Magill-Evans, J. and Koning, C. (2006) The quality of life of young men with Asperger syndrome: a brief report. Autism: The International Journal of Research and Practice [online]. 10 (4), pp.403-414. [Accessed 04/12/2012] Jones, R.S.P., Zahl, A. and Huws, J.C. (2001) First-hand accounts of emotional experiences in autism: A qualitative analysis. Disability \& Society [online]. 16 (3), pp.393-401. Accessed 02/04/2011].

Kober, R., ed. (2010) Enhancing the Quality of life of people with intellectual Disabilities: From Theory to Practice. London New York: Springer 
McAlolan,G.M., Daley. E., Kumari.V., Critchley.H.D., van Amelsvoort.T., Suckling.J., Simmons.A., Greenwood.K., Russell.A., Schmitz.N., Happe. P., Howlin.P. (2002). Brain anatomy and sensory motor gating in Asperger Syndrome. Brain A Journal of Neurology. 125 (7). Pp. 1594-606 (Accessed 27/03/18) Accessed 14/09/2011]. McGillivray, J.A., Lau, A., Cummins, R.A. and Davey, G. (2009) The utility of the Personal Wellbeing Index Intellectual Disability Scale in an Australian sample. Journal of Applied Research in Intellectual Disabilities [online]. 22 (3), pp.276-286.

Persson, B. (2000) Brief Report: A longitudinal study of quality of life and independence among adult men with autism. Journal of Autism \& Developmental Disorders [online]. 30 (1), pp.61. [Accessed 01/09/2012].

Plimley, L.A. (2007) A review of quality of life issues and people with autism spectrum disorders. British Journal of Learning Disabilities [online]. 35 (4), pp.205213

Punshon, C. and Skirrow, P. \& Murphy, G. (2009) The not guilty verdict: psychological reactions to diagnosis of Asperger Syndrome in adulthood. Autism : The International Journal of Research and Practice. 13 (3), pp.265-283.

Rapley, D. (2006) Quality of Life: Concept, Policy and Practice. London and New York: Routledge.

Rosenthal, M., Wallace, G., Gregory, L., Lawson, R.,Wills, M.C.,Dixon,E., Banjamin, E., Kenworthy, L. (2013) Impairments in real-world executive function increase from childhood to adolescence in autism spectrum disorders. Neuropsychology. 27 (1) pp.13-18. 
Schalock, R.L. (2010) The measurement and use of quality of life-related personal outcomes. In: Kober, R., ed. (2010) Enhancing the quality of life with people with Intellectual Disabilities. From Theory to Practice. London: Springer, pp.3-16.

Schwartz, C. and Rabinovitz, S. (2003) Life satisfaction of people with intellectual disability living in community residences: perceptions of the residents, their parents and staff members. Journal of Intellectual Disability Research [online]. 47 (2), pp.7584. [Accessed 05/03/2013].

Sheldrick, R.C., Neger, E.N., Shipman, D. and Perrin, E.C. (2012) QoL of adolescents with autism spectrum disorders: concordance among adolescents' selfreports, parents' reports, and parents' proxy reports. Quality of Life Research: An International Journal of Quality of Life Aspects of Treatment, Care and Rehabilitation [online]. 21 (1), pp.53-57. [Accessed 04/03/2013].

Shipman, D.L., Sheldrick, R.C. and Perrin, E.C. (2011) Quality of life in adolescents with autism spectrum disorders: reliability and validity of self-reports. Journal of Developmental and Behavioral Pediatrics: JDBP [online]. 32 (2), pp.85-89. [Accessed 04/02/2012].

Saldaña, D., Alvarez, R.M., Lobatón, S., Lopez, A.M., Moreno, M. and Rojano, M. (2009) Objective and subjective Quality of life in adults with autism spectrum disorders in southern Spain. Autism: The International Journal of Research and Practice [online]. 13 (3), pp.303-316. [Accessed 14/09/2013].

van Heijst, B.F. and Geurta, H.M. (2014) QoL in autism across the lifespan: A metaanalysis. Autism: The International Journal of Research and Practice [online]. DOI: 10.11771362361313517053. [Accessed 03/03/2014]. 
Verri, A., Cummins, R.A., Petito, F., Vallero, E., Monteath, S., Gerosa, E. and Nappi, G. (1999) An Italian-Australian comparison of QoL among people with intellectual disability living in the community. Journal of Intellectual Disability Research [online]. 43 (6), pp.513-522. [Accessed 02/03/2011] Zapft, W. (1984) Individuelle wohlfahit und wahrgenommeme lebensqailitat, in Glatzer, W. Zapft, Lebensqulitat in der Bundesrepublick Duetchland. Objektive Lebenssqulitat und subjektives wohlbefinden. Frankfurt/New York pp13-26. 